\title{
Simulation of interface behavior between FRP bars and concrete by an elastic-plastic theory via FEM
}

\section{Simulação do comportamento da interface entre barras de FRP e concreto por uma teoria elasto-plástica via MEF}

D. S. BRISOTTO a

daiabrisotto@yahoo.com.br

E. BITTENCOURT eduardo.bittencourt@ufrgs.br

V. M. R. D. BESSA vichy@ufrgs.br

\section{Abstract}

An elastic-plastic behavior is considered to simulate the interface rupture between grooved, helical wrapped and sand coated helical wrapped bars made of Fiber Reinforced Polymer (FRP) and concrete. Interface properties are obtained comparing results of the model with pull-out experiments. Properties obtained related to grooved bars are similar to properties known for ribbed steel bars. In this case, interface rupture behavior does not depend on bar properties. In case of both helical wrapped bars, on the other side, interface behavior is actually changed by FRP bar characteristics. The advantage of the present formulation is its capability to calculate splitting tractions, responsible for bulk concrete failure.

Keywords: concrete, FRP bars, plasticity, finite element.

\section{Resumo}

Um comportamento elasto-plástico é considerado para simular a ruptura da interface entre barras (ranhurada, helicoidal e helicoidal com areia)de fibra polimérica reforçada (FRP) e o concreto. As propriedades da interface são obtidas comparando os resultados do modelo com ensaios de arrancamento. As propriedades obtidas para a barra ranhurada são similares às propriedades conhecidas das barras de aço nervuradas. Neste caso, o comportamento em ruptura da interface não depende das propriedades da barra. Para as duas superfícies helicoidais, por outro lado, o comportamento da interface é realmente alterado pelas características da barra de FRP. A vantagem desta formulação é a capacidade de calcular trações de fissuração, responsáveis pela ruína do volume de concreto.

Palavras-chave: concreto, barras de FRP, plasticidade,elementos finitos. 


\section{Introduction}

Steel bars have been widely employed in reinforced concrete structures due to its efficiency and cost-effectiveness. However, certain environmental conditions can lead to corrosion of these bars and, consequently, the deterioration and even the progressive collapse of structural elements. In these situations, the use of fiber reinforced polymer (FRP) as reinforcement in concrete structures has been considered as an alternative in the latter decades due to its high corrosion resistance, high strength-weight relation and cost efficiency. FRP can be used in different manners as a reinforcement: internally as a replacement of the steel bars, externally or near surface. The present work focuses on the first case.

Just as in the case of steel bars, the bond between FRP bars and concrete is an aspect of fundamental importance on structural behavior. There are different types of fibers (glass, carbon and aramid) and a wide variety of surface finishes (sand coated, grooved, ribbed, wrapped, etc.) that may change bond behavior. These characteristics of FRPs are not yet standardized either, so to model bond behavior in such cases is challenging. Experiments sometimes lead to conflicting results as well. For instance, some researchers [1-3] concluded that FRP bar surfaces have an effect on the bond strength, while the findings of others $[4,5]$ showed the opposite.

In general bond stress is characterized by its relation with bar slip. In the case of FRP, pre-defined mathematical expressions have been proposed for these relations, with parameters being obtained by experiments [6-12]. For instance, the American Code ACI440.1R-06 [8] and the Japanese Design Code JSCE [9] provide expressions for bond-slip that are a function of four key factors: concrete strength, bar diameter, concrete cover and bar location, but they do not depend on the surface finishing of the bars. On the other side, Canadian Codes $[10,11]$ do introduce some surface effect on bond-slip relations.

However, relations based only on bond stresses are unable to take into account confinement effects that may change bond behavior drastically. An alternative way to obtain bond-slip relation for FRP bars including confinement effects would be to consider an elasticplastic model for the interface. Presumedly the first application of the elastic-plastic model was made by Guo and Cox [13]. Baky et al. [14] also used this type of model but applied it to concrete structures externally strengthened by FRP plates. Lundgren and Gylltoft [15] used this methodology to study bonding between ribbed steel bars and concrete. In [15] two yield (or failure) surfaces are formulated. One surface is related to concrete failure due to shearing and crushing by bar ribs and occurs when there is enough confinement. This type of failure is usually called simply pull-out. The other yield surface is related to failure by friction. This kind of failure typically occurs when splitting or longitudinal cracks develop at bulk concrete due to insufficient confinement and for this reason is called splitting. The distinction between failure modes is important because failure by splitting tends to be much more fragile than failure by pull-out. The present work uses the Lundgren and Gylltoft [15] methodology to explore the rupture of the interface between FRP bars and concrete and to obtain the evolution of interface properties.

A direct application of ribbed steel bar models to FRP bars is not straightforward, though. The bond failure in both cases is not necessarily the same [16-20]. The process can be much more complex in the case of FRP because outer layers of the bars may deform or be damaged during pull-out. For instance, it is now well-known that, when sufficient confinement is provided, both concrete and FRP ribs are sheared [17, 21]. If concrete has high strength, damage will develop predominantly at the ribs. This kind of failure can be seen in Figure 1, where horizontal dashed lines indicate rupture surfaces, and it will be called here "type I". For low strength concrete, failure behavior tends to be more similar to pull-out failure observed in steel bars, or concrete is predominantly damaged. This kind of failure will be called here "type II" and it is also depicted in Figure 1. A third and more catastrophic possible failure mode is delamination (type III in Figure 1), but this situation will not be addressed in the present work. Baena et al. [1] also stressed that surface finishing may change failure process and its effect is more important for high strength concrete. Several failure models for the interface FRP-concrete have been proposed since the end of the last century [19-24]. However the model proposed in this work is unique in the sense that friction effects are separated from interface damage.

Only glass fibers and indented bars are taken into account in this work (morphologic definitions follow Baena et al. [1]): grooved fin-

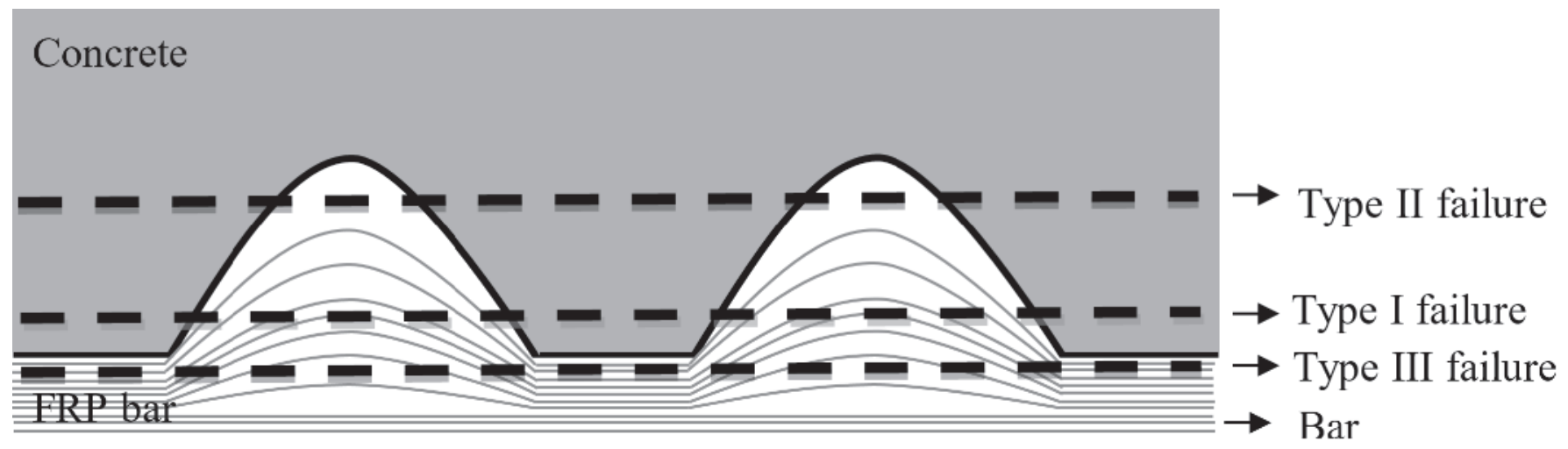

Figure 1

Schematic view of the FRP-concrete interface. Horizontal dashed lines indicate possible rupture surfaces in the case of pull-out failure (adapted from [17]) 
ishing (GF), helical wrapped finishing (HWF) and helical wrapped with sand coated finishing (HWSCF). Using the yield-surfaces defined in Lundgren and Gylltoft [15], the main goal of this work is to obtainnew interface properties for FRPbars, based on the fitting with experimental results. Also a new rupture model for the interface FRP-concrete is sought, where variables such as confinement is also contemplated. All experiments cited and used in this work were taken from the literature.

In section 2 the elastic-plastic model is described; in section 3 simulations are made in order to fit experimental results; a discussion on how rupture and interfaces properties evolve is made in section 4. Section 5 shows how splitting effects change with FRP finishing. Final remarks are presented in section 6 . Sub-indexes refer to tensorial components; super-indexes $e$ and $p$ indicate elastic and plastic components, respectively, and super-index $T$ indicates transposed tensor.

\section{Elastic-plastic interface formulation}

Bond behavior is governed by tractions $t_{\mathrm{i}}$ at the interface between concrete and bars. The tangential component $\left(t_{t}\right)$ corresponds to bond tractions, while the normal component $\left(t_{n}\right)$ corresponds to splitting tractions, with $t_{\mathrm{i}}=\left(t_{\mathrm{n}}, t_{\mathrm{t}}\right)^{\top}$.

Total deformation increments $\left(d u_{i}\right)$ are the sum of elastic deformation increments $\left(d u_{\mathrm{i}}^{e}\right)$ and plastic or dissipative deformation increments $\left(d u_{i}^{\mathrm{p}}\right)$ as follows:

$d u_{\mathrm{i}}=d u_{\mathrm{i}}^{\mathrm{e}}+d u_{\mathrm{i}}^{\mathrm{p}}$

where $d u_{\mathrm{i}}=\left(d u_{\mathrm{n}}, d u_{\mathrm{t}}\right)^{\top} \cdot t_{\mathrm{i}}$ is a function of elastic deformations and incrementally calculated as:

$d t_{\mathrm{i}}=D_{\mathrm{ij}} d u_{\mathrm{j}}^{\mathrm{e}}$

where $D_{\mathrm{ij}}$ is the elastic matrix andcan be considered a cohesion matrix containing the stiffness of linear springs attached to both sides of the interface.

In order to calculate plastic deformations, elastic limits (yield functions) are adopted following Lundgren and Gylltoft [15] as:

$F_{1}=\left|t_{\mathrm{t}}\right|+\mu t_{\mathrm{n}}=0$

$F_{2}=t_{t}^{2}+t_{n}^{2}+c t_{n}=0$

Originally the authors [15] considered that function $F_{1}$ represented failure by friction (splitting failure), where $\mu$ is the friction coefficient. $F_{2}$ represented concrete damage by compression (pull-out failure), for a limit stress $c$. Details regarding the latter function can be found in ref. [15], but basically it is obtained by equilibrium of compressive forces, which are associated to the resultant of $t_{\mathrm{n}}$ and $t$ tractions, near the interface. By postulate, the same equations for functions $F_{1}$ and $F_{2}$ are kept in this work. Representation of eqs. (3) and $(4)$ in $t_{n}, t_{t}$ space is seen in Figure 2.

If $F_{2}>0$, plastic deformation increments $d u_{i}^{p}$ are calculated as follows:

$d u_{\mathrm{i}}^{\mathrm{p}}=d l \partial F_{2} / \partial t_{\mathrm{i}}$

$d \lambda$ is a plastic multiplier to be determined. Therefore plastic deformation is normal to $F_{2}=0$. If $F_{1}>0$. a non-associated flow rule is assumed or: $d u_{\mathrm{i}}^{\mathrm{p}}=d \lambda \partial G / \partial t$

where

$G=\left|t_{\mathrm{t}}\right|+\eta t_{\mathrm{n}}=0$

Therefore plastic deformation is normal to $G=0 . \eta$ is taken equal to 0.04 in all cases. This value was obtained for ribbed steel bars [25] and it will be considered the same value in the present work. If both functions are greater than zero, plastic deformation direction goes toward the vertex of $F_{1}=0$ and $F_{2}=0$ surfaces.

Eqs. (1-7) describe a classic elastic-plastic problem associated to the interface, where $d \lambda$ is the unknown to be obtained. As application to the finite element method is aimed in this work, surface elements are introduced at the interface concrete-bar. As only axissymetric applications will be made in this work, the interface surface is modeled as a line. The surface elements have four nodes where, initially, two are coincident with the other two creating a zero-thickness (unidimensional) element. Tractions calculated by the procedure above can be then spatially integrated in the surface finite elements, resulting nodal forces. These nodal forces are added to other finite element forces that comes from volumetric elements. Equilibrium is achieved using a Newton-Raphson iterative scheme.

In order to complete formulation, elastic $\left(D_{i j}\right)$ and plastic $(\mu, \mathrm{c})$ properties must be defined. Elastic properties follow the definitions used for ribbed steel bars [25]. So, the equation for the elastic matrix $D_{i \mathrm{ij}}$ is defined as follows:

$D_{i j}=E_{c}\left[\begin{array}{cc}K_{11} & -\operatorname{sgn}\left(u_{t}^{e}\right) K_{12} \\ s y m & K_{22}\end{array}\right]$

where $E_{c}$ is the elastic modulus for concrete and $K_{11}, K_{12}$ and $K_{22}$ are elastic constants of the interface. $K_{22}$ depends only on geometrical definitions of the bar:

$K_{22}=\frac{t_{\mathrm{t}}}{u_{\mathrm{t}}^{\mathrm{e}}}=\frac{2 A^{\prime}}{\pi \emptyset l_{\mathrm{k}}^{2}}$

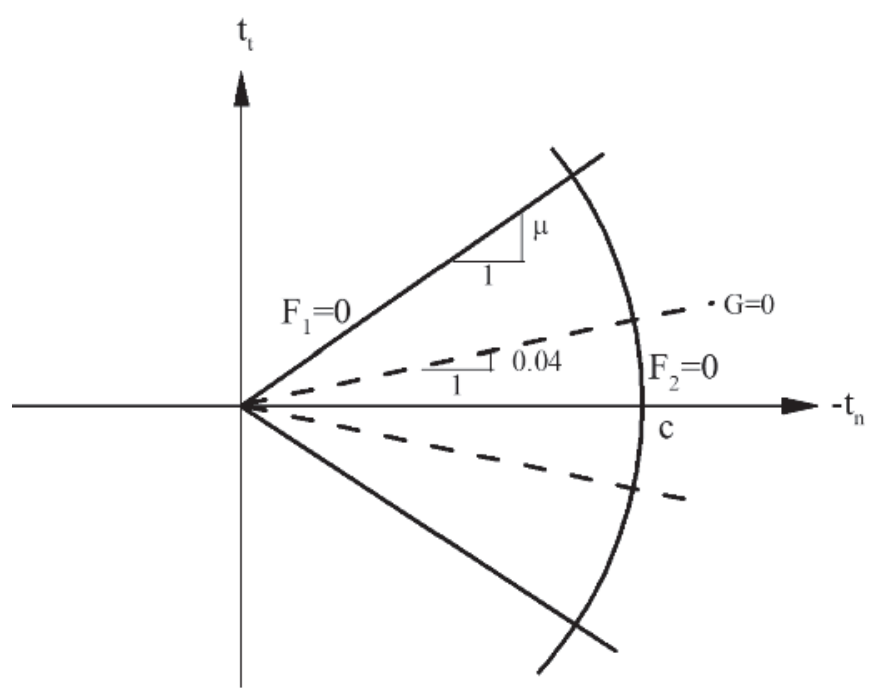

Figure 2

Elastic limits $F 1=0$ and $F 2=0 . G=0$ function is also shown 

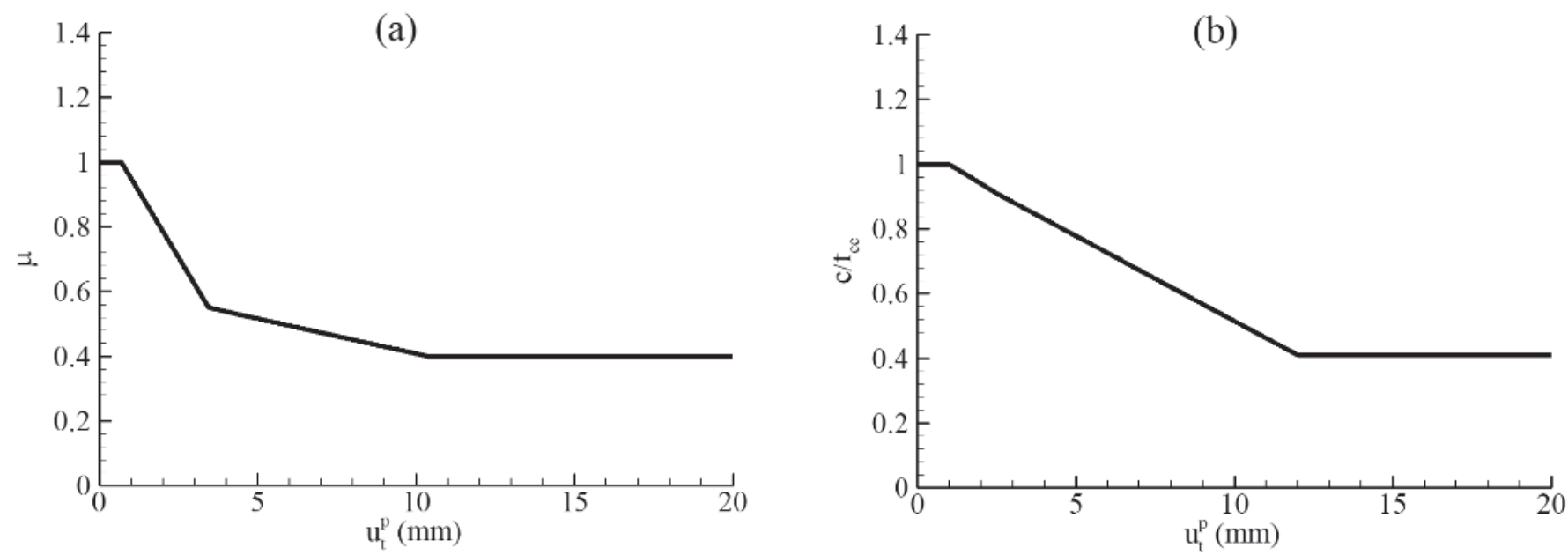

Figure 3

$\mu(a)$ andc (b) as a function of plastic slip for ribbed steel bars $[15,25]$

where $A^{\prime}$ is the area of the ribs projected transversely, $\phi$ is the bar diameter, $I_{k}$ is the longitudinal distance between the centers of the ribs. $K_{12}$ depends on the maximal friction of the interface $\mu_{\max }$, which depends on the bar surface finishing. Its value is obtained by calibration with experimental results, as discussed in section 4 . Although the term $\mu_{\max }$ is related to the yield surface $F_{2}$, tractions $t_{\mathrm{n}}$ calculated from this term is still considered an elastic term.

$\kappa_{12}=0.5 K_{22} / \mu_{\max }$

The term $D_{12}$ in eq. (8) takes into account compressive tractions resulting of the bar pulling process. To avoid an asymmetric elastic matrix, as used in ref. [25], the term $D_{21}$ is considered equal to $D_{12}$. The effect on $t_{t}$ caused by the introduction of the term $D_{21} u_{n}$ is minimal because $u_{n}$ is several orders of magnitude smaller than $u_{t}$. As a consequence, numerical results using eq. (8) or an asymmetric version, where $D_{21}=0$, are very similar.

When $u_{n}$ is negative $K_{11}$ is only a penalty factor to avoid inter-penetration between FRP and concrete. An arbitrarily high value can be then used. For values of $u_{\mathrm{n}}$ greater than $0.07 \mathrm{~mm}$, a value of $8 \mathrm{~m}^{-1}$ is proposed (this value is an average of previously values used for ribbed steel bars [25], ranging from 5 to $11 \mathrm{~m}^{-1}$ ). A linear relation is used for intermediate values of $u_{\mathrm{n}}$.

$\begin{array}{ll}K_{11}=150 \mathrm{~m}^{-1} & ; \quad u_{\mathrm{n}} \leq 0 \\ K_{11}=\left(0.0105-0.142 \mathrm{u}_{\mathrm{n}}\right) 10^{3} / 0.07 & ; \quad 0<u_{\mathrm{n}}<0.07 \mathrm{~mm} \\ K_{11}=8 \mathrm{~m}^{-1} & ; \quad u_{\mathrm{n}} \geq 0.07 \mathrm{~mm}\end{array}$
Plastic properties $\mu$ and $c$ as functions of the plastic slip are defined in Figure 3, for ribbed steel bars. $\mu$ is determined from experiments where cylinders of concrete are encased by steel tubes and $c$ is obtained from the post-peak compression stress-strain curve for concrete [15].

One of the main issues of this work is: How these properties are defined and how they evolve with sliding when FRP bars replace ribbed steel bars? Definition of $\mu$ function is now taken as the variation of friction coefficient between concrete and FRP bars. It takes into account the geometry of the bars. Definition of $c$ function is now taken as the post-peak crushing behavior of concrete or both concrete and FRP, depending on failure type. For type II failure the $c$ function is then known and it is equal to the function seen in Figure 3 (b). But would be very difficult to obtain $c$ functions directly from a compression experiment in the case of type I failure. Then comparisons of results obtained from the model with pull-out experiments are used as a guideline to have an insight regarding these properties. In the next section (3), numerical results calibrated to experiments are shown. In section $4, \mu$ andc functions obtained as a result of this calibration process are shown and discussed.

In all cases studied in this work, bars are pulled by monotonic displacements. In the case of steel bars, unloading effects using the elastic-plastic model described in this work are studied in ref. [25].

Table 1

Properties of concrete and bars [1]

\begin{tabular}{|c|c|c|c|c|c|c|c|c|c|c|c|c|}
\hline \multirow{2}{*}{\multicolumn{9}{|c|}{ Bars }} & \multicolumn{4}{|c|}{ Concrete } \\
\hline & & & & & & & & & \multicolumn{2}{|c|}{ C1 } & \multicolumn{2}{|c|}{ C2 } \\
\hline $\begin{array}{l}\text { Surface } \\
\text { treatment }\end{array}$ & $\begin{array}{c}\phi \\
(\mathrm{mm})\end{array}$ & $\begin{array}{c}f_{y} \\
(M P a)\end{array}$ & $\begin{array}{c}I_{k} \\
(\mathrm{~mm})\end{array}$ & $\begin{array}{c}A^{\prime} \\
\left(\mathrm{mm}^{2}\right)\end{array}$ & $\begin{array}{c}\mathrm{K}_{22} \\
\left(\mathrm{~mm}^{-1}\right)\end{array}$ & $\mu_{\max }$ & $\begin{array}{c}\mathrm{K}_{12} \\
\left(\mathrm{~mm}^{-1}\right)\end{array}$ & $\begin{array}{c}E_{s} \\
\text { (MPa) }\end{array}$ & $\begin{array}{c}f_{c c} \\
(M P a)\end{array}$ & $\begin{array}{c}E_{c} \\
(M P a)\end{array}$ & $\begin{array}{c}f_{c c} \\
(\mathrm{MPa})\end{array}$ & $\begin{array}{c}E_{\mathrm{c}} \\
(\mathrm{MPa})\end{array}$ \\
\hline GF & 12 & 1000 & 9 & 29.34 & 0.017 & 0.32 & 0.027 & 60000 & 29.35 & 28350 & 50.5 & 33000 \\
\hline \multirow{2}{*}{ HWF } & 8 & 689 & 18.39 & 36.63 & 0.008 & 1.2 & 0.003 & 46000 & - & - & 46.15 & 32100 \\
\hline & 12 & 689 & 16.02 & 46.03 & 0.0095 & 1.2 & 0.004 & 46000 & 29.34 & 28350 & 47.89 & 32430 \\
\hline HWSCF & 16 & 655 & 19.6 & 24.48 & 0.007 & 1 & 0.0035 & 40800 & 30.0 & 28517 & 49.55 & 32750 \\
\hline
\end{tabular}




\section{Numerical simulations}

In this section, the pull-out tests performed by Baena et al. [1] are used to calibrate properties of the proposed model. In all case studied in the present work failures occurred by pull-out, without delamination. The average bond stress is defined as:

$\tau=P / \pi \phi I_{\mathrm{b}}$

where $P$ is the tensile load applied to bar, $\phi$ is the bar diameter and $I_{\mathrm{b}}$ is the embedded length. In all cases $I_{\mathrm{b}}=5 \phi$. All concrete specimens are cubes with $200 \mathrm{~mm}$ sides. Mechanical properties are reproduced in Table 1. Bulk concrete and bars are considered elastic-linear, being all non-linearity taken at concrete-bar interfaces. $f_{\mathrm{y}}$ and $E_{\mathrm{s}}$ are the yield stress and longitudinal elastic modulus for FRP, respectively. $f_{c c}$ and $E_{c}$ are compression strength and longitudinal elastic modulus for concrete, respectively.

For numerical analyzes, the problem is considered axisymmetric with the same cover of the experiments. Only half of the geometry is modeled due to axisymmetry. The bar is modeled by four-node quadrilateral finite elements and concrete by three-node triangles in a cross-diagonal pattern. In all cases 1960 volumetric finite elements are used and are uniformly distributed. Unidimensional interfacial elements are also uniformly distributed throughout $I_{\text {b }}$. Number of interfacial finite elements depends on bar diameter: 16 elements for $\phi=16 \mathrm{~mm} ; 12$ elements for $\phi=12 \mathrm{~mm}$; and 10 elements for $\phi=8 \mathrm{~mm}$. A typical mesh is depicted in Figure 11. The figure also shows boundary conditions: bar is pulled by prescribed displacements, with concrete being blocked at the same side bar is pulled. Elastic parameters $K_{22}$ (see Eq. 9) and $K_{12}$ (Eq. 10) are also given in Table 1.

Functions $\mu$ and $c$ are obtained for $\phi=12 \mathrm{~mm}$ in the case of HWF. Case $\phi=8 \mathrm{~mm}$ was analyzed using the same functions.

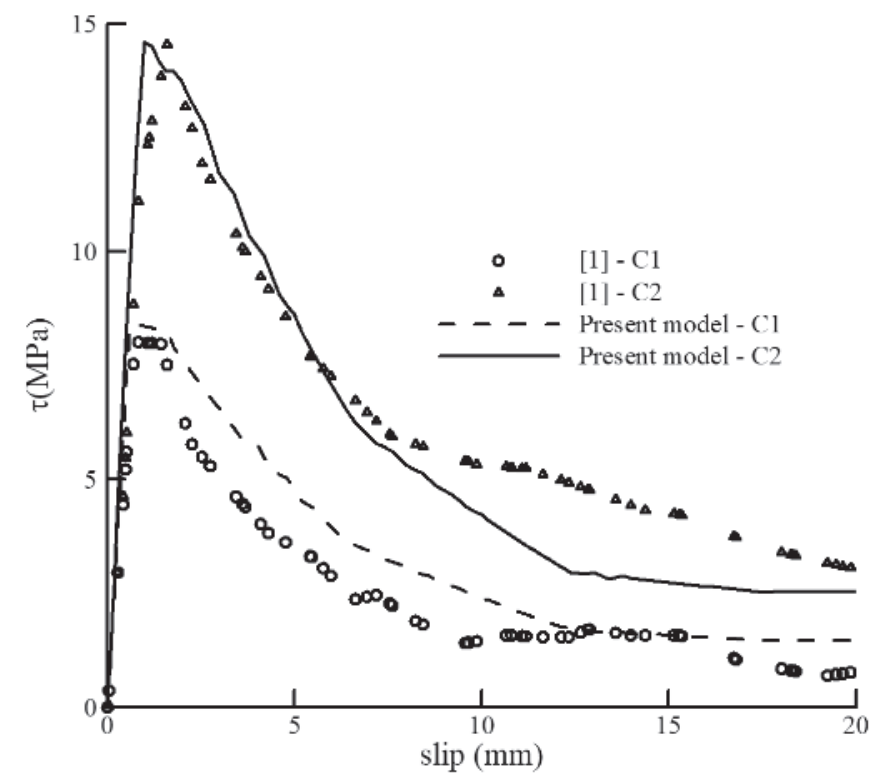

Figure 4

Numerical and experimental [1] average bond stress-slip curves for GF bars
The average bond stress-slip relations obtained for GF bars are shown in Figure 4. The pre-peak function is approximately linear and then a relatively fast drop in bond is seen after peak. This kind of behavior is sometimes called slip-weakening [19]. It can be observed also that bond strength increases almost linearly with concrete strength. As depicted in the figure, a good fitting is observed between experiments and the numerical model.

The average bond-slip relations obtained numerically and experimentally for HWF bars are presented in Figure 5 for $\phi=12 \mathrm{~mm}, \mathrm{C} 1$ and $\mathrm{C} 2$ concrete. A good fitting overall is again visible. In the case $\phi=8 \mathrm{~mm}, \mathrm{C} 2$ concrete, fitting is not so good for the softening part of the curve. The reason is that $c$ and $\mu$ functions were obtained specifically for $\phi=12 \mathrm{~mm}$. However the model is able to predict the bond strength increase with diameter decrease reported also experimentally [1, 21].

The ascending branch of the bond-slip function for HWF bars is first linear, but then becomes non-linear before bond peak. For this reason this type of behavior is denominated slip-hardening. In general, the shape of bond stress-slip relation for these cases is significantly different from that seen before for GF cases. Under similar conditions, HWF cases present higher bond strength, which takes place for much larger slips when compared with GF.

Finally, Figure 6 presents the average bond stress-slip relations obtained for HWSCF bars. Overall relations are similar to HWF cases. Again a good agreement is possible between experiments and simulations although post-peak behavior is somewhat underestimated by numerical results. The origin for this difference in behavior is discussed in the next section, where a model for the interface rupture is described.

As seen, all bond-slip relations present softening. Despite that, convergence to equilibrium was possible by standard NewtonRaphson procedure as only prescribed displacements are applied to the bars.

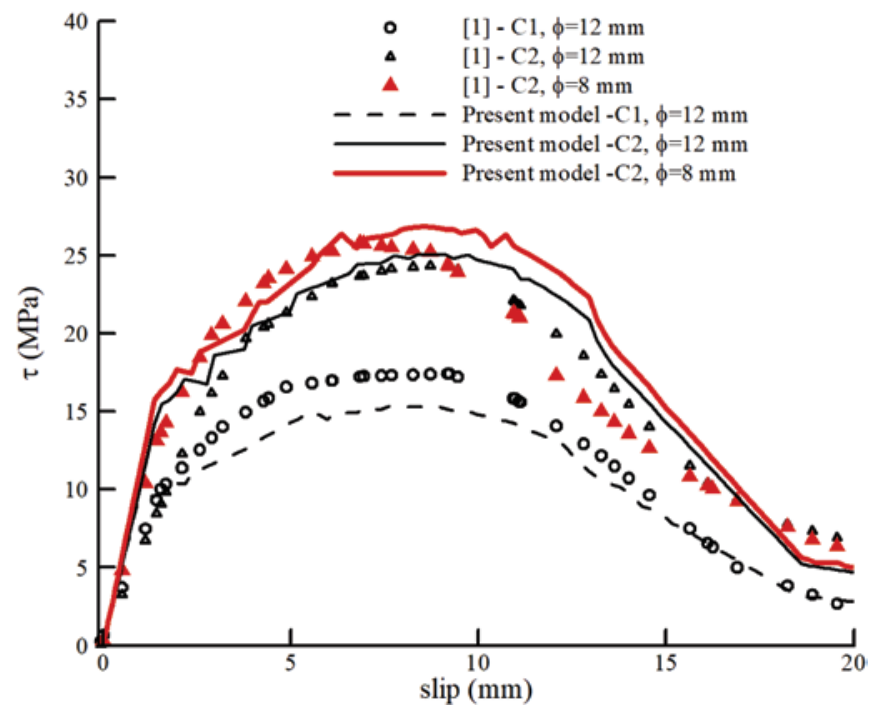

Figure 5

Numerical and experimental [1] average bond stress-slip relations for 12 and $8 \mathrm{~mm}$ diameter HWF bars 


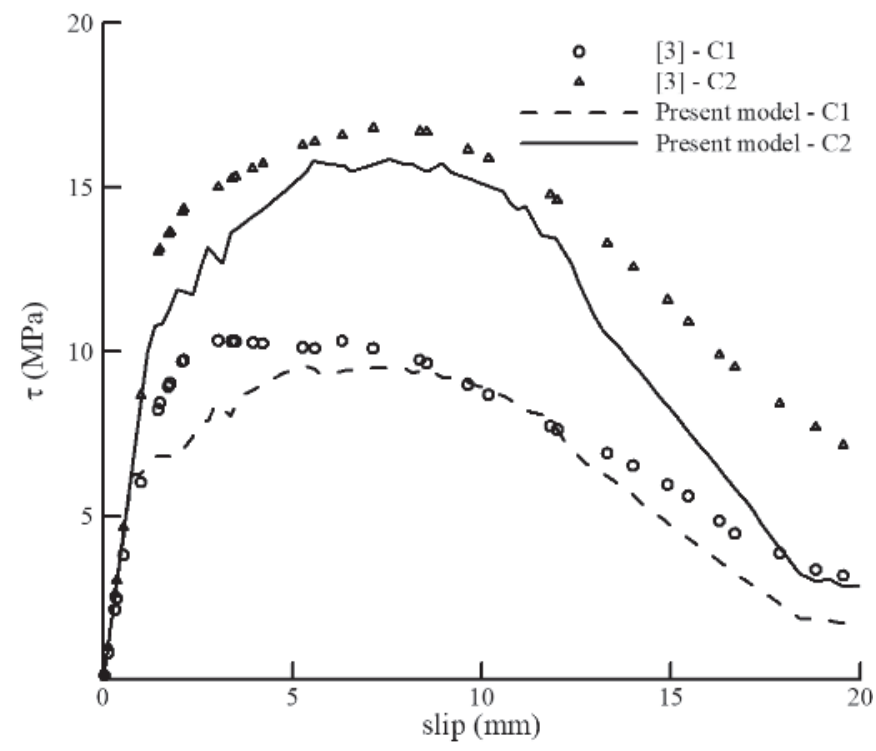

Figure 6

Numerical and experimental [1] average bond-slip curves considering HWSCF bars

\section{Interface rupture}

The interface rupture process for each case is described in this section. The procedure employed to estimate the values of the plastic properties is also described, according to bar finishing.

All bond-slip relations shown have in common an initial linear branch, where minimal damage is expected. Despite the presence of chemical adhesion [22], it is proposed in this work that friction effects are prevalent in this initial part. All material damage is considered to be associated only to property $c$. The same formulation for elastic properties is used (eqs. 8-11) so the relative elastic effect is the same in all cases.

\subsection{Grooved finishing}

The slope of the linear pre-peak branch observed in experimental bond versus slip relations (Figure 4 ) is a function of elastic properties and the initial $\mu$ value. This dependence can be explained observing Figure 7. Evolution of $t_{\mathrm{t}}$ with slipping is shown in Figure $7 \mathrm{a}$ for a typical point of the interface (values are negative due to convention arbitrated). Figure $7 \mathrm{~b}$ shows the coupling effect between $t_{\mathrm{n}}$ and $t_{\mathrm{t}}$. From this picture is possible to see that tractions remain on surface $F_{1}$ at the initial linear branch (0-1), so the slope of the prepeak depends on $\mu$. As deformations are still small, $\mu$ is constant and equal to $\mu_{\max }$ according to Figure $3 \mathrm{a}$. Relations in Figure 7a remains linear because the friction remains constant. It is possible then to obtain $\mu_{\max }$ by comparison of this slope with experiments (Figure 4). The result is $\mu_{\max } \cong 0.32$. This value is $68 \%$ lower than $\mu_{\text {max }}$ for ribbed steel bars ( $\cong 1$, Figure $3 a$ ).

At the peak of the bond stress in Figure 4, linear relation ends and damage by pull-out begins. This point defines the initial $c$ value, as traction combination should reach surface $F_{2}$ (point 1, Figure $7 \mathrm{~b}$ ). Calculating the radius of this point in $t_{\mathrm{n}}-t_{\mathrm{t}}$ space (Figure 7b) a value approximately equal to $f_{c c}$ is obtained. Then initial $c$ value for GF is coincident with the corresponding value for ribbed steel bars (Figure $3 b$ ). It is interesting to observe that the same peak bond value in Figure 4 could be obtained for a smaller value of $c$ and a greater value of $\mu$, but then numerical results could not be fitted with experiments in the pre-peak region. This conclusion assures that initial values of $\mu$ and $c$ proposed are coherent.

As an initial conclusion, it can be said that behavior of GF under pull-out failure is similar to ribbed steel bars or type II failure is prevailing, despite the fact that some damage at the FRP was reported by the experimentalists[1]. In fact, the slip-weakening type (a)

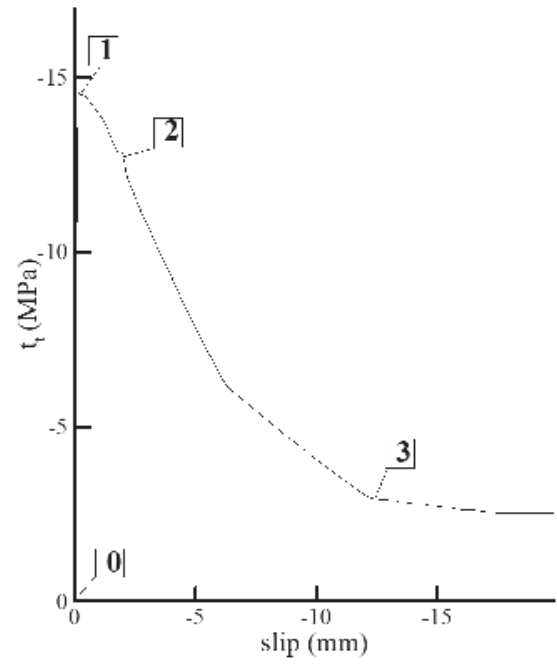

(b)

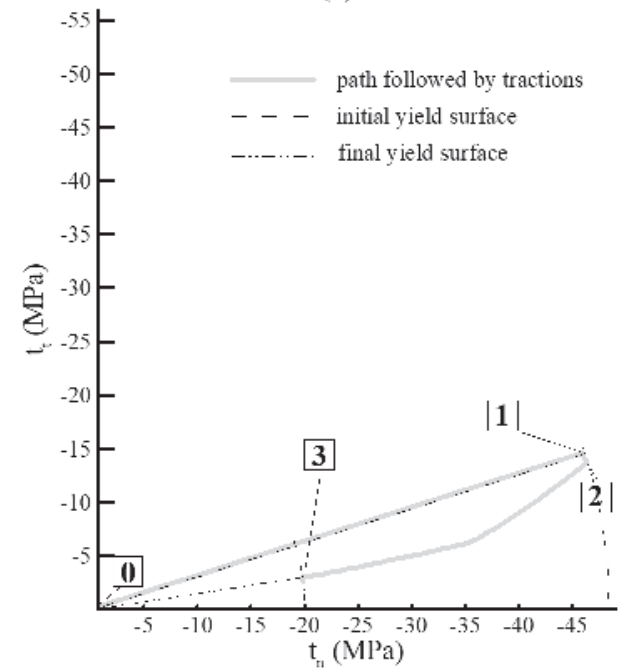

\section{Figure 7}

(a) Bond traction versus slip and (b) the path of tractions in space $t_{n}$ versus $t_{+}$for GF, concrete C2 and bar diameter $12 \mathrm{~mm}$, for a typical point of the interface 
(a)

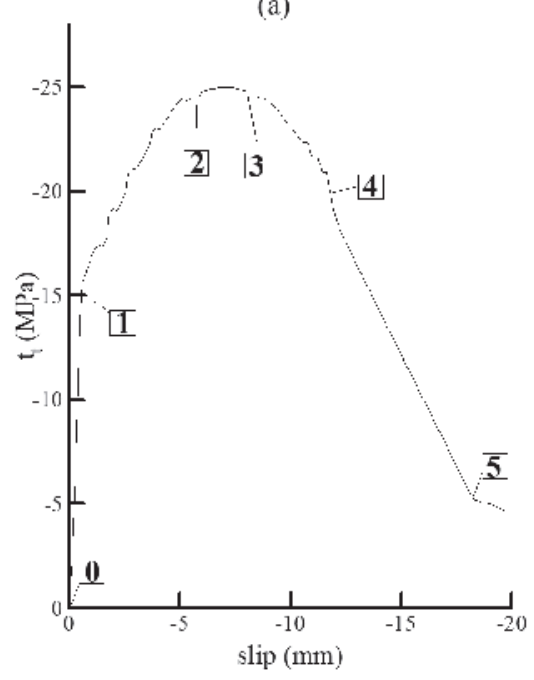

(b)

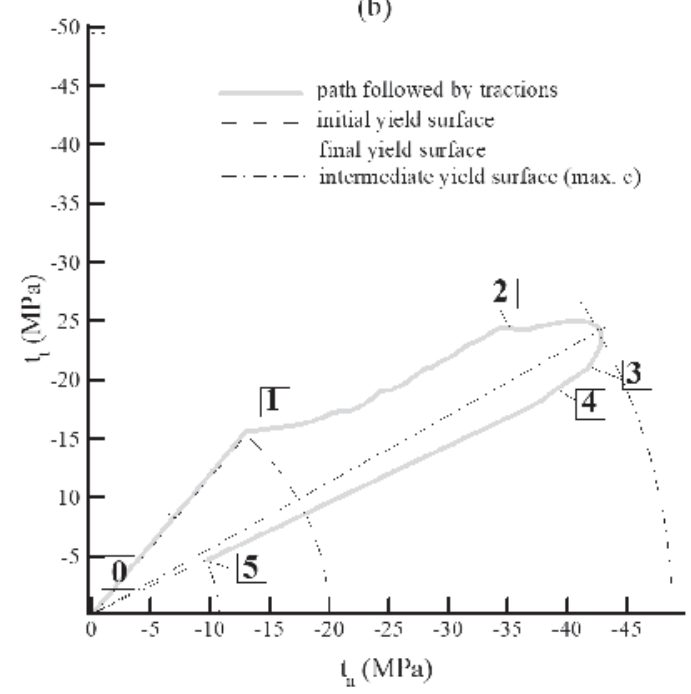

\section{Figure 8}

(a) Bond traction versus slip and (b) the path of tractions in space $t_{n}$ versus $t_{t}$ for HWF concrete C2 and bar diameter $12 \mathrm{~mm}$, for a typical point of the interface

of bond seen for this case is typically associated to steel bars [19]. The differences between the two cases, steel and GF bars, stem only from friction coefficient that is much lower in the latter case. So, as GF interface properties, the same functions seen in Figure 3 are adopted, except that $\mu$ function (Figure 3a) presents a $68 \%$ reduction overall.

Once plastic properties are now defined, it is possible to continue to follow the experiment depicted in Figure 7. A small region where $c$ is constant and $\mu$ decreases with plastic slip (1-2) is observed. So the rate of bond decrease immediately after peak is controlled by friction decrease. Behavior of this region is also associated to friction by Katz [19] in some cases. In region 2-3 both $c$ and $\mu$ decrease, as seen in Figure 3. However the decrease in $c$ function is more substantial, which is in accordance with pull-out failure. After point $3, c$ and $\mu$ are constant and characterize the residual bond strength. The residual value obtained by the model presents good fitting with experiments, indicating that the proposed plastic functions are consistent.

\subsection{Helical wrapped cases}

Figure 8a shows the evolution of $t_{\mathrm{t}}$ with slipping and Figure $8 \mathrm{~b}$ shows the coupling between tractions now for HWF. The diameter considered here for the bar is $12 \mathrm{~mm}$. As in GF cases, the initial slipping (0-1) is controlled by elastic properties and friction as tractions remain on $F_{1}$. From the slope of the linear pre-peak branch observed in experimental bond relations (Figure 5) it is possible to conclude that $\mu_{\max } \cong 1.2$, which is $20 \%$ higher than the value for ribbed steel bars. Based on this observation, the same friction function used for ribbed steel bars (Figure 3a) is adopted as an initial proposition, except that it is increased by a $20 \%$ factor overall. As in GF bars, the point where linear relation ends provides the initial value of $c$ (point 1, Figure 8). This initial value for HWF cases is much lower than $f_{c c}$ (approximately $50 \%$ lower), so obviously the pull-out process in this case is not only dependent on concrete crushing. Therefore type I failure should be prevailing in this case. A hardening effect in $c$ function is also necessary in region 1-2 because $\mu$ decreases but the bond effect increases (Figure 8a). These observations indicate that a completely newc function must be proposed. A proposition for $c$ function for HWF is shown in Figure 9 and it can be separated in two zones:

a) Pre-peak zone: As already established, pre-peak begins for a value $50 \%$ lower than initial value for ribbed steel bars

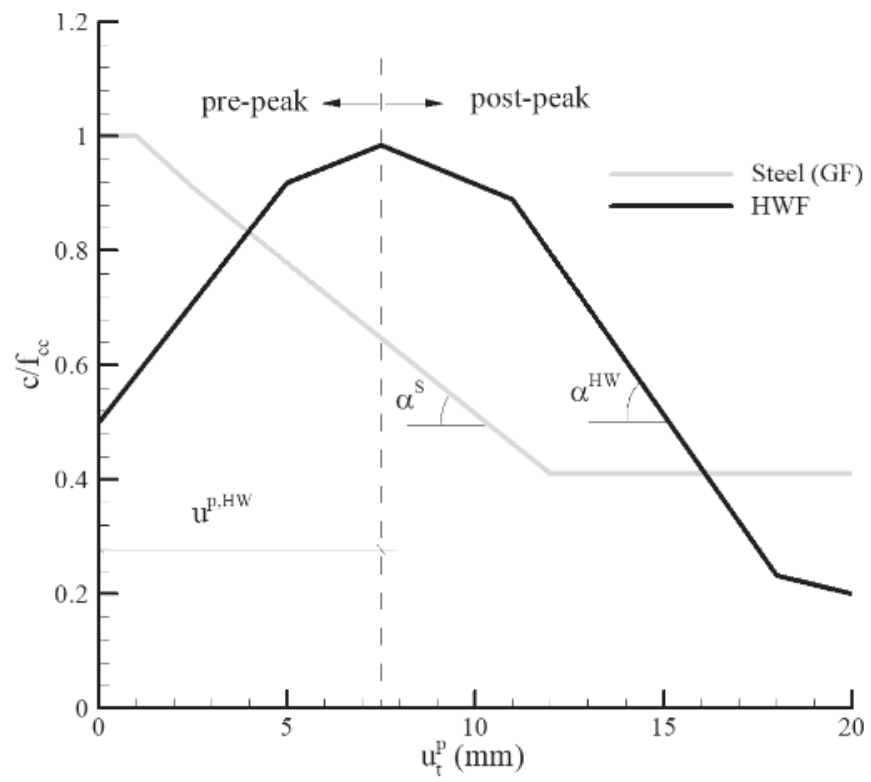

Figure 9

c function for HWF. Corresponding function for steel and GF bars is also shown 
(Figure 3b, shown again in Figure 9 to facilitate comparisons). This lower value is associated to some damage at the interface because it is followed by a stiffness decay in bond tractions, as seen in Figure 8a branch 1-2. Nonetheless a mechanical interlock is in effect as bond continues to increase with slip. This hardening is generally linked to anchor effects associated to ribs in shearing process [20]. A peak occurs between points 2-3 in Figure 8a. A value approximately equal to $f_{c c}$ is reached calculating the radius of the peak in $t_{\mathrm{n}}-t_{\mathrm{t}}$ space (Figure 8b). Therefore maximal value of $c$ should attains $f_{c c}$ value. (It is interesting to note that, as in GF case, the value of $t_{t}$ alone is far off concrete strength andit is possible to conclude that concrete is damaged only because the model considers the coupling between tractions $t_{\mathrm{n}}$ and $t_{\mathrm{t}}$ ). Another characteristic of this function refers to the plastic slip at the peak ( $u^{\mathrm{p}, \mathrm{HW}}$ in Figure 9), which is independent of the $f_{c c}$ in the cases considered. Therefore the increase in concrete strength is not spreading damage at FRP side, otherwise $u^{\mathrm{p}, \mathrm{HW}}$ would decrease when $f_{c c}$ increases. This characteristic of $c$ function must have a limit, but it is valid in the range of materials studied herein.

b) Post-peak zone: This zone is where the pull-out failure takes place effectively. The slope of this zone is defined by angle $\alpha^{\mathrm{HW}}$ (Figure 9). In the case of type II failure, $a^{\mathrm{HW}}$ should be similar to slope of $c$ for steel bars, $a^{s}$. This is the case of GF bars studied in item 4.1. In the present case, as a type I failure is in play, curve fitting with experiments leads to a steeper $c$ function (higher $\alpha^{\mathrm{HW}}$ ) or interface deteriorates faster with plastic slip.

Another difference between the curves in Figure 9 relates to the fact that HWF interface continues to deteriorates for larger $u^{\mathrm{p}}$ values than GF $\left(u^{p}=12 \mathrm{~mm}\right)$. The reason for this behavior is related to larger $I_{k}$ values in HWF cases (see Table 1 ).

As a result of $\mu$ and $c$ definition, it is possible now to continue to follow the path of tractions in Figure 8. In region 2-3-4, $c$ passes by a maximal value and then decreases, but $\mu$ is always decreasing. Therefore, again in the zone right after peak, a friction effect is in play. After (4), only $c$ decreases and $\mu$ remains constant. Hence,

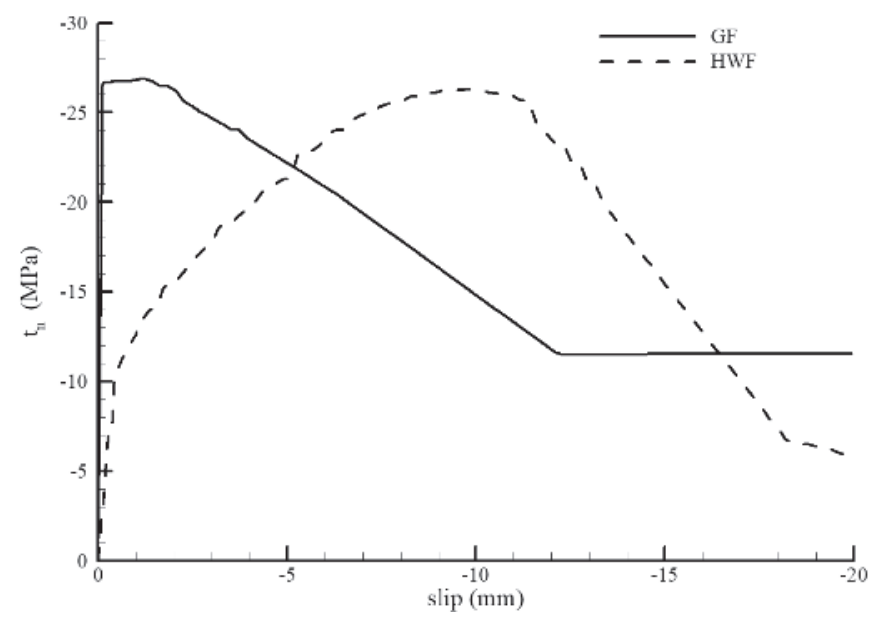

Figure 10

Splitting traction versus slip for GF and HWF, $\phi=12 \mathrm{~mm}$ decay in bond from this point is dominated by shrinking of $F_{2}$ surface, as expected in a failure by pull-out. In (5) residual strength is reached and is consistent with experiments.

\subsection{Sand coated cases}

HWSCF bars have a similar behavior as discussed for HWF bars. Using the same reasoning for the two previous cases analyzed, it is possible to conclude that values of $\mu$ and $c$ should be slightly reduced when compared with values used for HWF. One reason for this reduction can be related to the larger diameter considered for HWSCF cases (16 mm versus $12 \mathrm{~mm}$ ). As a result $\mu$ function is coincident with that used for ribbed steel bars, Figure 3a, and $c$ function is similar to HW function depicted in Fig 9, except with a $20 \%$ reduction overall.

The model is able to fit experiments until bond strength is reached for both types of concrete used ( 1 1 and $\mathrm{C} 2$ ), according to Figure 6 . However, post-peak behavior indicates that a somewhat smaller value for $\alpha^{\mathrm{HW}}$ would provide a better fitting with experiments. Therefore the level of damage on HWSC surfaces, in the cases considered, is slightly smaller than for HW surfaces.

\section{Splitting tractions}

The methodology permits to investigate the evolution of splitting tractions $t_{n}$. They can not be calculated by mainstream procedures available for bond estimation [6-12] and normally can not be easily obtained by experiments. Figure 10 depicts the evolution of $t_{\mathrm{n}}$ for GF and HWF with slip (concrete C1, $\phi=12 \mathrm{~mm}$ ). It is observed that $t_{n}$ evolves in a similar way to $t_{t}$ in each case, with GF case peaking at the onset of the damage and HWF case presenting a peak for larger values of slipping. However, in these cases bonding is much larger for HWF than for GF (see Figs 5 and 4), but Figure 10 indicates that level of splitting tractions is similar. Therefore bond tractions can not be used to estimate splitting tractions.

Besides the interface phenomena studied in this work, traction combinations at the interface define also stresses in bulk concrete. In Figure 11 distribution of hoop stresses $\left(\sigma_{33}\right)$ is shown for a $15 \mathrm{~mm}$ bar displacement $(\delta)$. In the left side results for GF interface are seen and in the right side results for HWF interface are shown. Only the right side of the specimen is actually modeled in all cases. Then GF results depicted in Figure 11 was obtained by mirroring the mesh around the symmetry line. Mesh and boundary conditions are also shown in Figure 11. Sliding of the bars is not the same due to different interface stiffnesses in each case. GF bar slipped approximately $14.8 \mathrm{~mm}$ and HWF bar $13.9 \mathrm{~mm}$. For this reason HWF bar appears to be longer than GF bar inFigure 11. For these particular values of slipping, $t_{n}$ is much larger in the HWF case (see Figure 10). As a consequence, positive hoop stresses are much higher in the HWF case in this moment of the pull-out test. Positive values also extend much deeper inside bulk concrete in this case. Splitting cracks in reinforced concrete take place once positive hoop stresses around bars are greater than concrete tensile strength beyond certain distant taken from the bar [26]. As a result, the present model is able to detect automatically if splitting failure is occurring (see [25] for more details). However, in none case analyzed in this work this type of failure occurred, which is consistent with experimental reports [1]. 


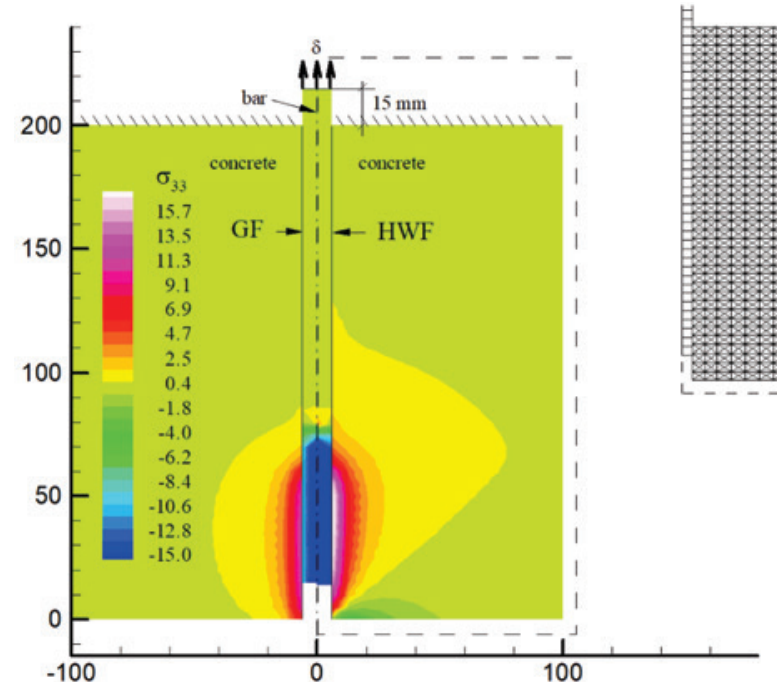

Figure 11

Distribution of hoop stresses in concrete and bar using interfaces for GF (left) and HWF (right).

Stresses are in MPa and all dimensions are in $\mathrm{mm}$. Boundary conditions used are also shown. Mesh used is depicted in the detail at right

\section{Conclusion}

In this work, a model based on previously developed theories, see ref. [15] and [25], was used to simulate the behavior of the interface between indented glass FRP bars and concrete. As a result, it was possible to establisha new rupture model for the interface that takes into consideration the confinement effect.Interface properties $\mu$ and $c$ were also estimated from experiments. It is concluded that:

- For GF bars, $c$ function has the same value as in ribbed steel bars (Figure $3 b$ ), indicating that pull-out failure is mainly controlled by type II failure (Figure 1). Friction $\mu$, on the other side, is much smaller than corresponding function for steel bars.

- For HWF and HWSCF bars, $\mu$ values are comparable to those for steel bars but $c$ values are quite different (Figure 9), indicating a type I failure (Figure 1).

- The $\mu$ function is important to define the initial slope of the bond-slip relation as well as its residual value. It was considered independent of $f_{\mathrm{cc}}$ (Figure 3a). $\mu$ function variations are also important to define the slope of the bond-slip relation in the region immediately after peak.

- Post-peak softening of the bond-slip relation is dominated by $c$ post-peak. If there is no major damage at the bar surface (type II failure), the slope of $c$ post-peak should be similar to that for steel bars ( $\alpha^{s}$, Figure 9$)$. Substantial damage at the bar side (type I failure), should increase this slope.

- $c$ functions in all cases showed a direct dependence on concrete strength $f_{\mathrm{cc}}$ (Figure 9) for the experimental cases analyzed. For HW cases, slip at the peak $\left(u^{\mathrm{p}, \mathrm{HW}}\right)$ did not change with $f_{c c}$.

The properties described above for $c$ and $\mu$ are not intended to be general and are approximately representative of the experiments done by Baena et al. [1] or similar concrete-bar combinations. More experiments need to be analyzed in order to have an accurate representation of these properties. However, this work demonstrates that FRP-concrete rupture can be represented in details by the elastic-plastic model described in section 2, considering different types of bar surfaces.

Loading considered in the applications of this model is monotonic. Behavior under loading-unloading conditions still needs to be investigated. Besides bond tractions, splitting tractions are also an outcome of the model (Figure 10). This is one considerable advantage of the proposed model regarding current methods available to model the FRPconcrete interface. As a consequence, it is possible to have a more complete picture of concrete stresses around the interface and failure of bulk concrete (Figure 11) by using the present methodology.

\section{Acknowledgements}

The authors gratefully acknowledge the financial support provided by Brazilian Government through CNPq.

\section{References}

[1] BAENA M, TORRES L, TURON A, BARRIS C (2009) Experimental study of bond behaviour between concrete and FRP bars using a pull-out test. Compos Part B Eng 40(8):784-97.

[2] HAO Q, WANG Y, HE Z, OU J (2009) Bond strength of glass fiber reinforced polymer ribbed rebars in normal strength concrete. Constr Build Mater 23:865-71.

[3] YAN F, LIN Z, YANG M (2016) Bond mechanism and bond strength of GFRP bars to concrete: A review. Compos B Eng 98:56-69.

[4] WAMBEKE B, SHIELD C (2006) Development Length of Glass Fiber-Reinforced Polymer Bars in Concrete. $\mathrm{ACl}$ Struct J 103(1):11-7.

[5] MOSLEY CP, TUREYEN AK, FROSCH RJ (2008) Bond strength of nonmetallic reinforcing bars. $\mathrm{ACl}$ Struct Journal 105(5):634-42.

[6] MALVAR LJ (1994) Bond stress-slip characteristics of FRP rebars. Report TR- 2013-SHR. Naval Facilities Engineering Service Center.

[7] COSENZA E, MANFREDI G, REALFONZO R (1997) Behavior and modeling of bond of FRP rebars to concrete. $J$ Compos Constr 1(2):40-51.

[8] ACl Committee $440 \mathrm{ACl} 440.1 \mathrm{R}-06$ (2006) Guide for the design and construction of concrete reinforced with FRP bars. American Concrete Institute.

[9] JSCE (1997) Recommendation for design and construction of concrete structures using continuous fibre reinforcing materials. Research Committee on Continuous Fiber Reinforcing Materials, Japan Society of Civil Engineers.

[10] CAN/CSA S806-12 (2012) Design and construction of building components with fibre-reinforced polymers. Canadian Standards Association.

[11] CAN/CSA S6-14 (2014) Canadian Highway Bridge Design Code. Canadian Standards Association.

[12] AMETRANO D (2011) Bond characteristics of glass fibre reinforced polymer bars embedded in high performance and 
ultra-high performance concrete. Dissertation, Ryerson University.

[13] GUO J, COX JV (2000) An interface model for the mechanical interaction between FRP bars and concrete. J Reinf Plast Compos 19:15-33.

[14] BAKY HA, EBEAD U, NEALE K (2012) Nonlinear micromechanics-based bond-slip model for FRP/concrete interfaces. Eng Struct 39:11-23.

[15] LUNDGREN K, GYLLTOFT K (2000) A model for the bond between concrete and reinforcement. Mag of Concr Res 52(1):53-63.

16] CHAALLAL O, BENMOKRANE B (1993) Pullout and bond of glass-fibre rods embedded in concrete and cement grout. Mater Struct 26(3):167-75.

[17] ACHILLIDES Z, PILAKOUTAS K (2004) Bond behavior of fiber reinforced polymer bars under direct pullout conditions. J Compos Constr 8(2):173-81.

[18] TEPFERS R, LORENZIS LD (2003) Bond of FRP reinforcement in concrete - a challenge. J Mech Compos Mater 39(4):477-96.

[19] KATZ, A (1999) Bond mechanism of FRP rebars to concrete. Mater Struct 32:761-768.

[20] LEE JY, CHONG KY, CHEONG YG, KIM BI (2012) Bond stress-slip behaviour of two common GFRP rebar types with pullout failure. Mag Concrete Res 64:575-591.

[21] DAVALOS JF, CHEN Y, RAY I (2008) Effect of FRP bar degradation on interface bond with high strength concrete. Cem Concr Compos 30(8):722-30.

[22] AIELO MA, LEONE M, PECCE M (2007) Bond performances of FRP rebars-reinforced concrete. J Mater Civ Eng 19:205-13.

[23] COSENZA E, MANFREDI G, REALFONZO R (1997) Behavior and modeling of bond of FRP rebars to concrete. J Compos Constr 1:40-51.

[24] COX JV, COCHRAN KB (2003) Bond between carbon fiber reinforced polymer bars na concrete. II: computational modelling. J Compos Constr 7:164-71.

[25] BRISOTTO DS, BITTENCOURT E, BESSA VMRA (2012) Simulating bond failure in reinforced concrete by a plasticity model. Comput Struct 106:81-90.

[26] TEPFERS R (1979) Cracking of Concrete Cover Along Anchored Deformed Reinforcing Bars. Mag. Concrete Res 31:3-12. 